\title{
Antimicrobial resistance among invasive Haemophilus influenzae strains: results of a Brazilian study carried out from 1996 through 2000
}

S.T. Casagrande, I.M. Landgraf, A.M.M. Kobata, R.C. Zanella and S. Bokermann
Departamento de Bacteriologia, Instituto Adolfo Lutz, São Paulo, SP, Brasil

\section{Correspondence}

S.T. Casagrande

Seção de Bacteriologia

Instituto Adolfo Lutz

Av. Dr. Arnaldo, 351

01246-902 São Paulo, SP

Brasil

Fax: +55-11-3085-3505

E-mail: casasil@unisys.com.br

Publication supported by FAPESP.

Received September 13, 2001 Accepted August 13, 2002

\begin{abstract}
A total of 1712 strains of Haemophilus influenzae isolated from patients with invasive diseases were obtained from ten Brazilian states from 1996 to 2000. B-Lactamase production was assessed and the minimum inhibitory concentrations (MIC) of ampicillin, chloramphenicol, ceftriaxone and rifampin were determined using a method for broth microdilution of Haemophilus test medium. The prevalence of strains producing $\beta$-lactamase ranged from 6.6 to $57.7 \%$, with an overall prevalence of $18.4 \%$. High frequency of $\beta$-lactamase-mediated ampicillin resistance was observed in Distrito Federal (25\%), São Paulo (21.7\%) and Paraná (18.5\%). Of the 1712 strains analyzed, none was B-lactamase negative, ampicillin resistant. A total of $16.8 \%$ of the strains were resistant to chloramphenicol, and $13.8 \%$ of these also presented resistance to ampicillin, and only $3.0 \%$ were resistant to chloramphenicol alone. All strains were susceptible to ceftriaxone and rifampin and the $\mathrm{MIC}_{90}$ were $0.015 \mu \mathrm{g} / \mathrm{ml}$ and $0.25 \mu \mathrm{g} / \mathrm{ml}$, respectively. Ceftriaxone is the drug of choice for empirical treatment of bacterial meningitis in pediatric patients who have not been screened for drug susceptibility. The emergence of drug resistance is a serious challenge for the management of invasive $H$. influenzae disease, which emphasizes the fundamental role of laboratory-based surveillance for antimicrobial resistance.
\end{abstract}

\section{Introduction}

Haemophilus influenzae is a major cause of severe systemic infection in childhood. It is also the second most common etiological agent, after the pneumococci, of acute otitis media in preschool children $(1,2)$.

Before the first $H$. influenzae type $\mathrm{b}$ (Hib) polysaccharide vaccine was introduced in
Key words

- Haemophilus influenzae - Meningitis

- Antimicrobial resistance 
differences in the quality of Brazilian meningitis surveillance programs in each area (6). The incidence of Hib during the period from 1996 to 1999 in children under four years of age was 18.7 cases per 100,000 inhabitants (Health Ministry, National Health Foundation, National Program of Immunization, Immunization. Available at $<$ http://www.funasa.gov.br/imu/imu01.htm>).

Soon after its introduction in the 1990's, the Hib conjugate vaccine was only available from private clinics at a high cost. Thus, most of the population had no access to this efficient preventive measure. The Ministry of Health of Brazil introduced the Hib conjugate vaccine in the childhood immunization schedule in 1999 but the impact of large scale immunization has not yet been evaluated.

The problem of ampicillin resistance has become increasingly more frequent in $H$. influenzae. B-Lactamase-producing strains are more common in children than in adults (7). Plasmid-mediated extracellular TEM-1 type $\beta$-lactamase producer strains of $H$. influenzae were first reported in the early 1970's (8-10). Subsequently, H. influenzae strains producing a second type of B-lactamase called ROB-1 were described, although ROB-1 production was much less extensive than TEM production (11). More recently, $H$. influenzae strains referred to as B-lactamase-negative (BLNAR) have been described but are fortunately uncommon (1214).

The Adolfo Lutz Institute is a National Reference Center for Meningitis which receives, identifies and stores the strains isolated from meningitis cases from various Brazilian States which are sent to the Institute through the Central Public Health Laboratories, and from public hospitals in greater São Paulo.

The objective of the present investigation was to conduct an exploratory study on the samples received during the period from 1996 to 2000 in Brazil in order to set up a program of laboratory-based epidemiological surveillance as a function of the profile of antibiotic resistance and B-lactamase production by $H$. influenzae strains isolated from children with invasive disease.

\section{Material and Methods}

\section{Setting and study population}

The study included bacterial strains sent by the network of Central Public Health Laboratories located in several Brazilian states to the National Meningitis Reference Center, Adolfo Lutz Institute, Central Public Health Laboratory, São Paulo, SP, Brazil. The strains were isolated from patients admitted to the public hospital network and were submitted to routine microbiological analysis. The strains were from the following states: Bahia $(\mathrm{N}=324)$, Pernambuco $(\mathrm{N}=313)$, Ceará $(\mathrm{N}=10)$, Distrito Federal $(\mathrm{N}=268)$, Goiás $(\mathrm{N}=19)$, São Paulo $(\mathrm{N}=$ 557), Minas Gerais $(\mathrm{N}=31)$, Paraná $(\mathrm{N}=$ 119), Santa Catarina ( $N=45)$, and Rio Grande do Sul $(\mathrm{N}=26)$. All strains were isolated from patients with invasive disease. The percent of children up to 5 years old enrolled in this study was $75 \%$.

\section{Bacterial isolates and identification}

The study included $1712 \mathrm{H}$. influenzae strains received between 1996 and 2000. Of these, $87.4 \%$ were isolated from cerebrospinal fluid, $11.6 \%$ from blood, and $0.9 \%$ from pleural fluid. Isolates were identified by colony and cell morphology and by the demonstration of growth requirements for $\mathrm{V}$ and $\mathrm{X}$ factors. The $\mathrm{V}$ factor requirement was tested by observing the satellite phenomenon and the $\mathrm{X}$ factor dependence was determined by testing the ability to convert $\delta$ aminolevulinic acid into porphyrins. Strains were further characterized by biochemical reactions by the method of Kilian and Biberstein (15). Capsulated strains were 
serotyped by the method of Pitman (16) using slide agglutination with type-specific antisera a through $\mathrm{f}$.

\section{Antimicrobial susceptibility testing}

All strains were subcultured twice onto chocolate agar plates (Difco Laboratories, Detroit, MI, USA) and incubated at $37^{\circ} \mathrm{C}$ in $5 \% \mathrm{CO}_{2}$ for 18 to $24 \mathrm{~h}$ before testing. The minimum inhibitory concentration (MIC) of antimicrobial agents was determined by microdilution broth methods in Haemophilus test medium (cation-supplemented MuellerHinton Broth, BBL Microbiology Systems, Cockeysville, MD, USA) supplemented with $15 \mu \mathrm{g} / \mathrm{ml}$ bovine hematin, $15 \mu \mathrm{g} / \mathrm{ml}$ NAD and $5 \mu \mathrm{g} / \mathrm{ml}$ yeast extract (Difco) containing one of the following antimicrobial agents in two-fold dilutions: $0.06-64 \mu \mathrm{g} / \mathrm{ml}$ ampicillin, $0.015-16 \mu \mathrm{g} / \mathrm{ml}$ chloramphenicol, 0.001 $2 \mu \mathrm{g} / \mathrm{ml}$ ceftriaxone, and $0.007-8 \mu \mathrm{g} / \mathrm{ml}$ rifampin (17; Sigma, St. Louis, MO, USA). Antibiotic panels were prepared by dispensing media containing two-fold concentration increments of antimicrobial agents in a $50-\mu 1$ volume into 96-well plastic trays (Difco). Growth from 18- to 24-h cultures was suspended in distilled water and diluted to match the turbidity, corresponding to $0.5 \mathrm{McF}$ arland standard, and absorbance at $625 \mathrm{~nm}$ was read with a spectrophotometer. The suspension was further diluted 1:100 and added to the dilution trays to achieve a final inoculum of $5 \times 10^{5} \mathrm{CFU} / \mathrm{ml}$. Colony counts were performed to confirm the desired final inoculum (17). Immediately following inoculation, the microdilution panels were incubated at $37^{\circ} \mathrm{C}$ in ambient air for 20 to $24 \mathrm{~h}$. After incubation, the MIC was defined as the lowest concentration of an antimicrobial agent required for an organism to show no evidence of growth. According to the criteria of the National Committee for Clinical Laboratory Standards (17), the organisms were considered resistant/susceptible if the MIC were $\geq / \leq 4 / 1 \mu \mathrm{g} / \mathrm{ml}$ for ampicillin, $8 / 2 \mu \mathrm{g} / \mathrm{ml}$ for chloramphenicol, and $4 / 1 \mu \mathrm{g} / \mathrm{ml}$ for rifampin, and susceptible if the MIC were $\leq 2$ $\mu \mathrm{g} / \mathrm{ml}$ for ceftriaxone. Haemophilus influenzae ATCC 49247 was used as control.

\section{ß-Lactamase assay}

Production of B-lactamase was determined by the chromogenic cephalosporin method (10) using reconstituted lyophilized nitrocefin (Glaxo 87/312, Glaxo Research, Unipath Ltd., Hampshire, England). The test was considered positive if the yellow color changed to purple. Haemophilus influenzae ATCC 49247 was used as negative control and Staphylococcus aureus ATCC 29213 was used as positive control.

\section{Results}

\section{Biotypes and serotypes}

Among our samples we found 993 (58.0\%) strains belonging to biotype I, 663 (38.7\%) to biotype II and $56(3.3 \%)$ to biotypes III, IV, V and VI. Type b serotype accounted for $95.8 \%(1640 / 1712)$ of the strains, serotype a for $2.0 \%(34 / 1712)$, serotype $\mathrm{c}$ for $0.2 \%$ (3/1712), serotype $\mathrm{d}$ for $0.4 \%$ (6/1712), serotype e for $0.1 \%(2 / 1712)$, serotype for $0.4 \%$ (6/1712), and non-typable strains for $1.2 \%(21 / 1712)$.

\section{Antimicrobial resistance patterns}

The percent of resistant strains in several Brazilian states is shown in Table 1. The overall frequency of ampicillin-resistant strains that produced ß-lactamase was $18.4 \%$ (Table 2). The percent of B-lactamase-producing strains was $18.6 \%$ for children aged less than 5 years (208/1113). The frequency of B-lactamase-producing strains rose gradually from $15.3 \%$ in 1996 to $17.4 \%$ in 1997 , $18.6 \%$ in $1998,20.9 \%$ in 1999 , and $18.8 \%$ in 2000. The overall frequency of chloramphenicol resistance was $16.8 \%(287 / 1712)$, 
presenting the pattern shown in Table 1; $13.8 \%(236 / 1712)$ of these strains showed associated resistance to ampicillin and 3\% $(51 / 1712)$ of the strains showed resistance to chloramphenicol alone. The frequency of $\beta$ lactamase-producing strains ranged from 6.6 to $57.7 \%$ according to the various states.

Table 1. Distribution of antimicrobial resistance patterns of Haemophilus influenzae isolated from 1996 to 2000 in different Brazilian states.

\begin{tabular}{lcccc}
\hline State & No. of strains & \multicolumn{3}{c}{ No. (\%) of resistance pattern to } \\
\cline { 3 - 5 } & & $\begin{array}{c}\text { Only } \\
\text { ampicillin }\end{array}$ & $\begin{array}{c}\text { Only } \\
\text { chloramphenicol }\end{array}$ & $\begin{array}{c}\text { Chloramphenicol } \\
\text { and ampicillin }\end{array}$ \\
\hline Northeast & & & & \\
$\quad$ Bahia & 324 & $4(1.2)$ & $7(2.2)$ & $21(6.5)$ \\
$\quad$ Ceará & 10 & 0 & 0 & $5(50.0)$ \\
$\quad \begin{array}{l}\text { Pernambuco } \\
\text { Centralwest }\end{array}$ & 313 & $5(1.6)$ & $13(4.2)$ & $28(8.9)$ \\
$\quad$ Distrito Federal & 268 & $7(2.6)$ & $14(5.2)$ & $60(22.3)$ \\
$\quad$ Goiás & 19 & $2(10.5)$ & 0 & $5(26.3)$ \\
Southeast & & & & $79(14.1)$ \\
$\quad$ São Paulo & 557 & $42(7.5)$ & $14(2.5)$ & $14(45.1)$ \\
$\quad$ Minas Gerais & 31 & $3(9.6)$ & $1(3.2)$ & $17(14.3)$ \\
South & & & & $2(4.4)$ \\
$\quad$ Paraná & 119 & $5(4.2)$ & 0 & $5(19.2)$ \\
$\quad$ Santa Catarina & 45 & $1(2.2)$ & $2(4.4)$ & $236(13.8)$ \\
$\quad$ Rio Grande do Sul & 26 & $10(38.5)$ & 0 & \\
Total & 1712 & $79(4.6)$ & $51(3.0)$ & \\
\hline
\end{tabular}

The values used for the calculation of resistance, $\geq 4.0 \mu \mathrm{g} / \mathrm{ml}$ ampicillin, $\geq 8.0$ $\mu \mathrm{g} / \mathrm{ml}$ chloramphenicol, are in accordance with the National Committee for Clinical Laboratory Standards (17). The numbers given within parentheses are percent.

Table 2. Distribution of ß-lactamase-positive and -negative strains of Haemophilus influenzae isolated from 1996 to 2000 in different Brazilian states

\begin{tabular}{lrcr}
\hline State & $\begin{array}{c}\text { No. of } \\
\text { strains }\end{array}$ & $\begin{array}{c}\text { No. (\%) of } \\
\text { B-lactamase positive }\end{array}$ & $\begin{array}{c}\text { No. (\%) of } \\
\text { B-lactamase negative }\end{array}$ \\
\hline Bahia & 324 & $25(7.7)$ & $299(92.3)$ \\
Ceará & 10 & $5(50.0)$ & $5(50.0)$ \\
Pernambuco & 313 & $33(10.5)$ & $280(89.5)$ \\
Distrito Federal & 268 & $67(25.0)$ & $201(75.0)$ \\
Goiás & 19 & $7(36.8)$ & $12(63.2)$ \\
São Paulo & 557 & $121(21.7)$ & $436(78.3)$ \\
Minas Gerais & 31 & $17(54.8)$ & $14(45.2)$ \\
Paraná & 119 & $22(18.5)$ & $97(81.5)$ \\
Santa Catarina & 45 & $3(6.7)$ & $42(93.3)$ \\
Rio Grande do Sul & 26 & $15(57.7)$ & $11(42.3)$ \\
Total & 1712 & $315(18.4)$ & $1397(81.6)$ \\
\hline
\end{tabular}

The numbers within parentheses are percent.
Strains from Rio Grande do Sul and Minas Gerais showed the highest frequencies of $\beta$ lactamase production, corresponding to 57.7 and $54.8 \%$, respectively. Similarly, the lowest frequency $(6.7 \%)$ of $\beta$-lactamase-mediated ampicillin resistance was observed in Santa Catarina State. São Paulo State and Distrito Federal showed similar frequencies of B-lactamase-producing strains, corresponding to $21.7 \%$ and $25.0 \%$, respectively. Among strains isolated in the municipality of São Paulo the frequency of ß-lactamaseproducing strains was $18.9 \%$. Among the 1712 strains analyzed, none was BLNAR. Data concerning the $\mathrm{MIC}_{50}$ and $\mathrm{MIC}_{90}$ of $\beta-$ lactamase-positive and -negative strains are summarized in Table 3. All $H$. influenzae strains were extremely susceptible to ceftriaxone and rifampin, exhibiting $\mathrm{MIC}_{90}$ values of 0.015 and $0.25 \mu \mathrm{g} / \mathrm{ml}$, respectively.

\section{Discussion}

Since the late 1970's when antibiotic resistance increased among $H$. influenzae strains, ampicillin resistance, mainly that mediated by ß-lactamase, was the form of resistance most frequently found among these strains. In São Paulo municipality, Brazil, the prevalence of ampicillin resistance and B-lactamase-producing strains has already been reported, with a mean frequency of $13.8 \%$ $(18,19)$.

The present study shows that the overall frequency of $\beta$-lactamase producers in $H$. influenzae was $18.4 \%$. Similar results have also been obtained in collaborative international studies $(2,7,14)$. However, in studies carried out in Brazil, the mean frequency of $\beta$-lactamase producers was $12 \%$ among strains isolated from the respiratory tract, but these studies did not report the serotype of the isolates $(20,21)$. Doern et al. (7) detected a $12.1 \%$ frequency of $\beta$-lactamaseproducing strains among non-typable $H$. influenzae strains. The prevalence of ampicillin-resistant $\beta$-lactamase-producing strains 
has been increasing among non-typable $H$. influenzae in the United States (2). There is often an association between high frequencies of $\beta$-lactamase and production of the type b capsule and isolated meningitis strains, especially among patients aged 6 months to 6 years $(12,22)$. Our isolates showed a $95.9 \%$ frequency of type b strains and an 87.4\% frequency of samples isolated from cerebrospinal fluid. The $\beta$-lactamase-producing strains presented a $\mathrm{MIC}_{90}$ of $64 \mu \mathrm{g} / \mathrm{ml}$ for ampicillin and $16 \mu \mathrm{g} / \mathrm{ml}$ for chloramphenicol (Table 3), with most strains resistant to ampicillin being also resistant to chloramphenicol (Table 1). The resistance to ampicillin is coded by a plasmid which harbors the TnA transposons, and the transposition mechanism is important for the evolution to plasmids simultaneously carrying multiple resistance $(23,24)$. A better indicator of increasing resistance to B-lactam antibiotics among $H$. influenzae would be a significant shift in $\mathrm{MIC}_{90}$ values over a period of time $(24,25)$.

The overall frequency of resistance to chloramphenicol was $16.8 \%$, with only $3 \%$ of these strains being resistant to chloramphenicol alone, and $13.8 \%$ of these samples were resistant to ampicillin as well (Table 1). Chloramphenicol resistance in $H$. influenzae occurs worldwide, although the incidence of these strains tends to be lower than that of $\beta$ lactamase-producing strains (26). Spain is one of the countries where higher frequencies of antibiotic resistance have been documented. Among community-acquired bacterial isolates in particular, resistance frequencies are among the highest in the European Union (27).

During the 5 years of study, an increase was observed in the frequency of B-lactamase-producing strains from $15.3 \%$ in 1996 to $18.8 \%$ in 2000 . The increase of $\beta$-lactamase-producing strains that are resistant to ampicillin has been observed in other countries, with different percentages depending on the region studied $(2,7,12,14)$. Differ- ences were observed between overall frequencies of B-lactamase-producing strains from states located in different geographic regions. Probably the number of strains was scarce, with the States of Ceará, Minas Gerais, Goiás and Rio Grande do Sul presenting a smaller number of strains compared to the others, with a consequent possible bias being introduced into the data base. It is tempting to infer that this reflects geographic patterns of $ß$-lactamase production. Grouping of study centers into geographic regions was never done to demonstrate any consistent trends. More population data are necessary to perform a comparative analysis of geographic regions. A study involving medical centers throughout the United States showed that $\beta$-lactamase production is related to patient demographics rather than to geography (7).

The vast Brazilian territory with its different climatic and socioeconomic conditions may contribute to the differences in the percentage of $\beta$-lactamase production and in the profile of resistance to the antimicrobial agents studied. However, the number of samples investigated was not large enough to determine the significance of the results.

Lower frequencies of $\beta$-lactamase-mediated ampicillin resistance were observed in Santa Catarina (6.7\%), Pernambuco (10.5\%) and Bahia (7.7\%), the last two belonging to the same geographic region, unlike Santa Catarina which is located $3000 \mathrm{~km}$ to the South, with climatic conditions of a sub-

Table 3. Minimum inhibitory concentrations, $\mathrm{MIC}_{50}$ and $\mathrm{MIC} 90(\mu \mathrm{g} / \mathrm{ml})$, of ß-lactamasepositive and -negative Haemophilus influenzae strains isolated in Brazil between 1996 and 2000

\begin{tabular}{|c|c|c|c|c|c|c|}
\hline \multirow[t]{2}{*}{$\begin{array}{l}\text { Antimicrobial } \\
\text { agent }\end{array}$} & \multicolumn{2}{|c|}{$\begin{array}{l}\text { ß-Lactamase } \\
\text { positive }\end{array}$} & \multirow[t]{2}{*}{ Range } & \multicolumn{2}{|c|}{$\begin{array}{l}\text { ß-Lactamase } \\
\text { negative }\end{array}$} & \multirow[t]{2}{*}{ Range } \\
\hline & $\mathrm{MIC}_{50}$ & $\mathrm{MIC}_{90}$ & & $\mathrm{MIC}_{50}$ & $\mathrm{MIC}_{90}$ & \\
\hline Ampicillin & 16 & 64 & $(2-64)$ & 0.125 & 0.25 & $(0.015-0.25)$ \\
\hline Chloramphenicol & 8.0 & 16 & (0.03-16) & 0.5 & 1.0 & $(0.03-1.0)$ \\
\hline Ceftriaxone & 0.003 & 0.007 & $(0.001-0.015)$ & 0.003 & 0.015 & $(0.001-0.015)$ \\
\hline Rifampin & 0.125 & 0.25 & $(0.003-0.25)$ & 0.125 & 0.25 & $(0.003-0.25)$ \\
\hline
\end{tabular}


tropical zone, while states in the northern region have tropical climatic conditions. High frequencies of $\beta$-lactamase-mediated ampicillin resistance were observed in Distrito Federal (25\%), São Paulo (21.7\%) and Paraná (18.5\%). In São Paulo municipality, with a population of 9,713,692 million and a demographic density of $6,823.68$ inhabitants $/ \mathrm{km}^{2}$ (28), the overall frequency of B-lactamase production was $18.9 \%$ and the frequency during the period from 1989 to 1995 was $13.8 \%$ (19). The high resistance frequency in these states may perhaps be due to the fact that they comprise population strata with greater acquisitive power that may permit the purchase of antimicrobial agents, even though most of the samples were from public hospitals whose clients usually represent a low income population. The emergence of resistance to antimicrobial agents is becoming a major public health problem worldwide, especially in hospital-acquired infections. Infectious disease experts are particularly concerned because organisms resistant to available antimicrobial drugs have been isolated in hospitals worldwide (29). The high resistance frequency mainly in the city of São Paulo could be explained by the fact that this is an important economic center in the country with extensive national and international migration. With increasing travel and patient movement throughout the world, the situation exists for transmission of multidrug-resistant pathogens from one country or continent to another (30).

The States of Goiás, Ceará, Minas Gerais and Rio Grande do Sul recorded higher frequencies of $\beta$-lactamase production, i.e., 36.8, $50.0,54.8$, and 57.7\%, respectively. During the study period, these states recorded the lowest number of strains, reported in a nonsystematic manner, a fact probably representing bias of the data presented. In this respect, the implementation of a national system of public health laboratories is of vital importance for the recording of consistent data, standardization of the methods, priority of the surveillance system, and a constant interchange with reference laboratories so that the information will be as reliable as possible and yield less biased results. As suggested by Camargo (31), laboratory, clinical and epidemiological information about diseases of compulsory notification should be part of a single data bank managed by the coordination of epidemiological surveillance of each state.

In the present study, simultaneous resistance to ampicillin and chloramphenicol was observed in strains isolated in the different states. Distrito Federal and São Paulo State presented the highest frequencies. Resistance to more than one antimicrobial agent has been described in different microorganisms and in different countries $(25,32,33)$.

All strains were susceptible to ceftriaxone and rifampin with a $\mathrm{MIC}_{90}$ of 0.007 and 0.25 $\mu \mathrm{g} / \mathrm{ml}$ for $\beta$-lactamase-positive strains, respectively. Ceftriaxone is an antimicrobial agent recommended for the treatment of bacterial meningitis in pediatric patients who have not been screened for drug sensitivity. In developed countries, the choice for the treatment of meningitis caused by $\mathrm{H}$. influenzae strains is the use of third-generation cephalosporins to which resistance has not yet emerged $(12,13,34)$. Rifampin is an antimicrobial agent recommended by the Health Ministry for chemoprophylactic use by all house contacts of index cases, by day-care centers or schools where children are exposed, and at the time of hospital discharge by patients with house contacts involving children younger than 48 months (35).

Non- $\beta$-lactamase-mediated ampicillin resistance was an isolated occurrence among the $H$. influenzae strains studied; such strains are still very rare among ampicillin-resistant strains $(2,12,13)$. It has been postulated that BLNAR is associated with altered penicillin-binding proteins and might be due to the lower virulence of strains with abnormal penicillin-binding proteins (36). Frequently the strains are non-typable, mainly causing 
diseases of the respiratory tract, and having MICs in the low resistance range (37).

The emergence of drug resistance is a serious challenge for the management of invasive $H$. influenzae disease, which emphasizes the fundamental role of laboratorybased surveillance for antimicrobial resistance. Continued surveillance for resistance and susceptibility testing of $H$. influenzae is vital to maximize the benefits of antimicrobial therapy and to contain the spread of infection.

Public health measures to control antimicrobial resistance are costly, and funding them is difficult. Nonetheless, we need local, national and international surveillance programs, early warning systems, proper training for laboratory technicians, appropriate quality control programs and profi- ciency testing, improved microbiologic and epidemiologic capacities of health care facilities worldwide, and the ability to implement infection control activities (38).

\section{Acknowledgments}

We thank Dr. Kinue Irino for useful comments and for revising the manuscript. We are also indebted to Dr. Carmo Elias A. Melles, Meningitis Reference Center Coordinator, for valuable assistance, and to Dr. Maria C. Cunto Brandeleone for encouragement. We acknowledge the São Paulo State Hospital network for promptly sending the strains and biological fluid samples. We also acknowledge the Central Public Health Laboratories network for promptly sending the strains.

\section{References}

1. Bluestone CD, Stephenson JM \& Martin LM (1992). Ten-year review of otitis media pathogens. Pediatric Infectious Disease Journal, 11: S7-S11.

2. Doern GV, Brueggeman AB, Pierce G, Holley HP \& Rauch A (1997). Antibiotic resistance among clinical isolates of Haemophilus influenzae in the United States in 1994 and 1995 and detection of ß-lactamase-positive strains resistant to amoxicillin-clavulanate: results of a national multicenter surveillance study. Antimicrobial Agents and Chemotherapy, 41: 292-297.

3. Booy R \& Kroll JS (1997). Is Haemophilus finished? Journal of Antimicrobial Chemotherapy, 40: 149-153.

4. Bisgard KM, Kao A, Leake J, Strebel PM \& Wharton M (1998). Haemophilus influenzae invasive disease in the United States, 1994-1995: near disappearance of vaccine-preventable childhood disease. Emerging Infectious Disease, 4: 1-13.

5. Garpenholt O, Silfverdal S \& Levin L (1998). Economic evaluation of general childhood vaccination against Haemophilus influenzae type b in Sweden. Scandinavian Journal of Infectious Diseases, 30: 5-10

6. Ministério da Saúde (1998). Meningites em geral. In: Guia de Vigilância Epidemiológica. Fundação Nacional de Saúde, Brasília, DF, Brazil, Chapter 5.30.

7. Doern GV, Jorgensen JH, Thornsberry C
\& Preston DA (1986). Prevalence of antimicrobial resistance among clinical isolates of Haemophilus influenzae: a collaborative study. Diagnostic Microbiology and Infectious Disease, 4: 95-107.

8. Khan W, Ross S, Rodrigues S, Mather LA \& Saz AK (1974). Haemophilus influenzae type b resistant to ampicillin: a report of two cases. Journal of the American Medical Association, 229: 298-301.

9. Tomeh MO, Starr SE, McGowan JE, Terry PM \& Nahmias AJ (1974). Ampicillinresistant Haemophilus influenzae type $b$ infection. Journal of the American Medical Association, 229: 295-297.

10. Sykes RB \& Mathew M (1978). Methods for detecting beta-lactamase. In: Reeves DS, Phillips JD, Williams JD \& Were R (Editors), Laboratory Methods in Antimicrobial Chemotherapy. Churchill Livingstone, Edinburgh, UK, 64-69.

11. Mardowitz SM (1980). Isolation of an ampicillin-resistant, non-ß-lactamase-producing strain of Haemophilus influenzae. Antimicrobial Agents and Chemotherapy, 17: 80-83.

12. Jorgensen JH, Doern GV, Maher LA, Howell AW \& Redding JS (1990). Antimicrobial resistance among respiratory isolates of Haemophilus influenzae, Moraxella catarrhalis and Streptococcus pneumoniae in the United States. Antimicrobial Agents and Chemotherapy, 34: 2075-
2080.

13. Scriver SR, Walmsley SL, Kau CL, Hoban DJ, Brunton J, McGrer A, Moore TC \& Witwicki E (1994). Determination of antimicrobial susceptibility of Canadian isolates of Haemophilus influenzae and characterization of their ß-lactamase. Canadian Haemophilus Study Group. Antimicrobial Agents and Chemotherapy, 38: 1678-1680.

14. Manninen $R$, Houvinen $P$, Nissinen A \& The Finnish Study Group for Antimicrobial Resistance (1997). Increasing antimicrobial resistance in Streptococcus pneumoniae, Haemophilus influenzae and Moraxella catarrhalis in Finland. Journal of Antimicrobial Chemotherapy, 40: 387-392.

15. Kilian M \& Biberstein EL (1984). Haemophilus. In: Krieg NR \& Holt JG (Editors), Bergey's Manual of Systematic Bacteriology. 8th edn. Baltimore, MD, USA, 558569.

16. Pitman M (1931). Variation and type specificity in the bacterial species Haemophilus influenzae. Journal of Experimental Medicine, 53: 471-492

17. National Committee for Clinical Laboratory Standards (NCCLS) (1999). Performance Standards for Antimicrobial Susceptibility Testing: Ninth Informational Supplement M100-S9. National Committee for Clinical Laboratory Standards, Villanova, PA, USA. 
18. Rey LC \& Farhat CK (1997). Prevalência de Haemophilus influenzae resistente a ampicilina, cefaclor, cefotaxime, cloranfenicol e cotrimozaxol isolados de laboratórios na cidade de São Paulo. Jornal de Pediatria, 73: 26-31.

19. Casagrande ST, Vicente EJ, Landgraf IM \& Kobata AMM (2000). Antimicrobial resistance patterns of Haemophilus influenzae isolated from patients with meningitis in São Paulo, Brazil. Brazilian Journal of Medical and Biological Research, 33: 295-300.

20. Critchley IA, Thornsberry C, Piazzat G, Jones M, Hichey ML, Barth AL, Mendes C, Rossi FF, Sader HS, Teixeira LM \& Sahm DF (2000). Antimicrobial susceptibility of Streptococcus pneumoniae, Haemophilus influenzae and Moraxella catarrhalis collected from five centers in Brazil, 1997-98. Clinical Microbiology and Infectious Diseases, 6: 178-184.

21. Sader HS, Gales AC, Granacher TD, Pfaller MA, Jones RN and The SENTRY Study Group (Latin America) (2000). Prevalence of antimicrobial resistance among respiratory tract isolates in Latin America: Results from SENTRY antimicrobial surveillance program (1997-98). Brazilian Journal of Infectious Diseases, 4: 245-254.

22. Goldstein FW \& Acar JF (1995). Epidemiology of antibiotic resistance in Haemophilus influenzae. Microbial Drug Resistance, 1: 131-135.

23. Brunton J, Clare D \& Meire MA (1986). Molecular epidemiology of antibiotic resistance plasmids of Haemophilus species and Neisseria gonorrhoeae. Reviews of Infectious Diseases, 8: 713-724.

24. James PA, Lewis DA, Jordens JZ, Cribb J, Dawson SJ \& Murray AS (1996). The incidence and epidemiology of B-lactam resistance in Haemophilus influenzae. Journal of Antimicrobial Chemotherapy, 37:
737-746

25. Thornsberry C, Ogilvie PT, Holley HP \& Sahm DF (1999). Survey of susceptibilities of Streptococcus pneumoniae, Haemophilus influenzae, and Moraxella catarrhalis isolates to 26 antimicrobial agents: a prospective U.S. study. Antimicrobial Agents and Chemotherapy, 43: 2612-2623.

26. Johnson AW, Mookkolu AO \& Onile BA (1992). Chloramphenicol-resistant Haemophilus influenzae meningitis in young urban Nigerian children. Acta Paediatrica, 81: 941-943.

27. Baquero F \& Task Force of the General Direction for Health Planning of the Spanish Ministery of Health (1996). Antibiotic resistance in Spain: What can be done? Clinical Infectious Diseases, 23: 819-823.

28. IBGE: Brazilian Institute of Geography and Statistics. Available at <http:www. ibge.gov.br/home/estatistica/populacao/ censo2000/defaul.shtm>. Accessed August 24, 2001.

29. Richet HM, Mohammed J, McDonald LC, Jarvis WR \& International Network for the Study and Prevention of Emerging Antimicrobial Resistance (2001). Building communication networks: international network for the study and prevention of emerging antimicrobial resistance. Emerging Infectious Diseases, 7: 319322.

30. Cookson B, Johnson AP, Azaidan B, Paul G, Hutchinson G, Kaufmann M, Woodford N, Malde M, Walsh B, Yousef A \& Selkon $J$ (1995). International inter- and intrahospital patient spread of a multiple antibiotic-resistant strain of Klebsiella pneumoniae. Journal of Infectious Diseases, 171: 511-513.

31. Camargo MCC (1996). Doença meningocócica no município de São Paulo, no período de 1979 a 1993 endemia e epidemia. Master's thesis, Faculdade de Saúde Pública, USP, São Paulo, SP, Brazil.

32. Campos J, Torne SG, Gairi JMJ \& Fabregues I (1986). Multiple resistant Haemophilus influenzae type $b$ causing meningitis: Comparative clinical and laboratory study. Journal of Pediatrics, 108: 897-902.

33. Brandileone MCC, Di Fabio JL, Vieira VSD, Zanella RC, Casagrande ST, Pignatari AC \& Tomasz A (1998). Geographic distribution of penicillin resistance of Streptococcus pneumoniae in Brazil: genetic relatedness. Microbial Drug Resistance, 4: 209217

34. Klugman KP \& Madhi SA (1999). Emergence of drug resistance: impact on bacterial meningitis. Infectious Diseases Clinics of North America, 13: 637-646.

35. Ministério da Saúde (1998). Meningite por Haemophilus influenzae. In: Guia de Vigilância Epidemiológica. Fundação Nacional de Saúde, Brasília, DF, Brazil, Chapter 5.21

36. Clairoux N, Picard M, Brochu A, Rousseau N, Gourde P, Beauchamp D, Parr Jr TR, Bergeron MG \& Malouin F (1992). Molecular basis of the non-ß-lactamase-mediated resistance to ß-lactam antibiotics in strains of Haemophilus influenzae isolated in Canada. Antimicrobial Agents and Chemotherapy, 36: 1504-1513.

37. Woolfrey BF, Lally RT \& Ederer MN (1987). Evaluation of Haemophilus influenzae type $b$ systemic isolates for ß-lactamase and non- $ß$-lactamase mediated ampicillin resistance and for susceptibility to other antimicrobials. American Journal of Clinical Pathology, 88: 361-365.

38. Richet HM (2001). Better antimicrobial resistance surveillance efforts are needed. American Society for Microbiology, 67: 304-309. 